\title{
COVID-19: Apreciação de mudanças comportamentais com base nos preceitos do marketing social
}

\section{COVID-19: Assessment of behavioral changes based on the principles of social marketing}

\author{
Daniel Kamlot \\ ESPM/RJ, FGV/Ebape e PUC-Rio - Brasil \\ danielkamlot@yahoo.com.br \\ ORCID: https://orcid.org/0000-0002-6976-6333
}

\author{
Recebido: 12 Março 2021 \\ Revisado: 14 Abril 2021 \\ Aceito: 19 Agosto 2021
}

\begin{abstract}
Resumo
Objetivo do estudo: 0 presente estudo parte do cerne do marketing social, isto é, da alteração no comportamento dos indivíduos visando à obtenção de bem-estar social no longo prazo, para descrever o contexto de inserção das práticas de alteração do comportamento da sociedade na realidade brasileira, e relaciona as recomendações focadas no combate à pandemia do COVID-19 ao que é apregoado pelo marketing social. Metodologia: 0 foco nas abordagens comportamentais direcionadas ao enfrentamento da pandemia se deu por meio de uma pesquisa de abordagem qualitativa, seguindo uma estrutura lógica e reflexiva, em que se ressaltam a interpretação e a argumentação. Assim, foram enumeradas as práticas indicadas ao enfrentamento do recente surto de COVID-19, identificando aquelas que condizem com os preceitos do marketing social. Principais resultados: São apresentadas as principais recomendações relacionadas ao combate ao COVID-19, apreciações e ponderações, identificando a relação de tais recomendações às práticas de marketing social e como estas podem contribuir para gerar maior bem-estar no cenário de pandemia acarretado pelo COVID-19. Contribuição acadêmica: Apresenta-se como uma abordagem baseada em direitos humanos auxilia no gerenciamento de riscos e oportunidades, além de oferecer um método particularmente útil para lidar com questões desafiadoras inerentes ao marketing social, contribuindo na literatura sobre o tema. Observam-se, especificamente, elementos constituintes de aspectos do marketing social relacionados aos âmbitos social, psicográfico, político-legal e demográfico. Contribuição prática: Promove-se a compreensão de como uma abordagem baseada em direitos humanos apresenta aos profissionais de marketing social um guia prático cujas implicações incluem a facilitação do reconhecimento das expectativas da sociedade brasileira e a ajuda no desenvolvimento de maneiras mais sustentáveis de abordar problemas sociais.
\end{abstract}

Palavras-chave: COVID-19; marketing social; comportamento; bem-estar social.

\begin{abstract}
Purpose: The present study focuses on the core of social marketing, that is, the change in the behavior of individuals aiming at obtaining social welfare in the long term, to describe the context of insertion of the practices to change the behavior of society in the Brazilian reality, and relates the recommendations focused on combating the pandemic of COVID-19 to what is proclaimed by social marketing. Methodology: The focus on behavioral approaches aimed at coping with the pandemic took place through a qualitative research, following a logical and reflective structure, in which interpretation and argumentation are emphasized. Thus, the practices indicated for coping with the recent outbreak of COVID-19 were listed, identifying those consistent with the precepts of social marketing. Main results: The main recommendations related to combating COVID-19, appraisals and considerations are presented, identifying the relationship of such recommendations to social marketing practices and how they can contribute to generating greater well-being in the pandemic scenario caused by COVID-19. Academic contribution: It is shown how an approach based on human rights assists in the management of risks and opportunities, in addition to offering a particularly useful method for dealing with challenging issues inherent to social marketing, contributing to the literature on the subject. Specifically, elements that constitute aspects of social marketing related to the social, psychographic, political-legal and demographic spheres are presented. Practical contribution: the study provides an understanding of how a human rights-based approach presents social marketing professionals with a practical guide whose implications include facilitating the recognition of the expectations of Brazilian society and helping to develop more sustainable ways of addressing social problems.
\end{abstract}


Keywords: COVID-19; social marketing; behavior; social welfare.

\section{Introdução}

A partir da irrupção da crise mundial desencadeada pelo SARS-CoV-2, ou "novo coronavírus", responsável por causar a síndrome respiratória aguda COVID-19 (Van Bavel, 2020), muito mudou no cotidiano mundial e no brasileiro, em particular. Uma alteração nas ações e nos ânimos se mostra cada vez mais presente, com a busca pela manutenção da saúde e bem-estar das pessoas segundo práticas recomendadas por autoridades médicas e de saúde pública, seguindo políticas públicas e relacionadas à salubridade.

Ainda que diversas práticas mercadológicas tenham sido alteradas a fim de evitar uma paralisação na atividade econômica ou, ainda, para reduzir eventuais perdas contábeis antecipadas por organizações de variados portes, é possível notar que, de um ponto de vista relacionado ao marketing, muito da preocupação dos gestores tem como foco o ambiente de negócios, porém há uma crescente inquietação voltada a uma alteração nas atitudes e no comportamento dos indivíduos.

Desde os anos 1970, a comunidade acadêmica passou a compreender o marketing não apenas como uma atividade administrativa e econômica, mas também como um processo social (Abratt \& Sacks, 1988). Nesse processo, ocorreria uma percepção do marketing como sendo influenciado e influenciando os valores não-monetários de seus participantes e da sociedade em geral.

Um debate bastante frequente atualmente diz respeito a priorizar o mercado - e suas necessidades de desenvolvimento econômico - ou focar nas necessidades da sociedade em busca de bem-estar social. Tal discussão suscita a abordagem de alguns elementos componentes da vertente do marketing conhecida como marketing social, que tem o intuito de trazer mudanças benéficas aos membros de uma sociedade, derivadas de alterações comportamentais (Kamlot, 2012; 2017).

Os termos "marketing social" e "marketing societal" (ou "marketing societário") são, com certa frequência, tratados como similares por profissionais e acadêmicos do marketing. Entretanto, deve ser ressaltado que tais termos se referem a dimensões distintas na ciência do marketing. 0 marketing social tem um enfoque nas propriedades do marketing relacionadas à dimensão tecnológica, isto é, aquela referente à aplicação das técnicas do marketing em instituições comerciais e não comerciais para influenciar a aceitabilidade das ideias sociais (Kotler \& Zaltman, 1971), e concerne à influência sobre comportamentos, por meio de um processo de planejamento sistemático e com o uso de princípios e técnicas tradicionais de marketing, com a intenção de gerar um benefício positivo à sociedade (Kotler \& Lee, 2008). Assim, o marketing social não tem foco apenas em ideias, mas também em atitudes e comportamentos (Andreasen, 1994). 0 marketing societal, por outro lado, diz respeito à dimensão substantiva do marketing (Abratt \& Sacks, 1988). De uma forma sucinta, entende-se tal dimensão como focada não apenas na atuação de empresas e consumidores, mas também na sociedade, a qual é impactada pelo que ocorre entre clientes e empresas e depende de uma geração de bem-estar advinda da interação ocorrida entre tais atores (Kamlot \& Schmitt, 2015). Em resumo, o marketing social exige uma mudança de comportamento visando a obter bem-estar social, enquanto o marketing societal entende que a satisfação dos consumidores deve ser obtida, porém visando ao alcance de objetivos organizacionais - ou seja, neste caso haveria o objetivo de lucro, ainda que com foco na sociedade e nos impactos sobre esta advindos as atividades empresariais. No presente trabalho, o foco recai sobre os princípios do marketing social, uma vez que as mudanças comportamentais é que serão exploradas.

Assim, considerando o cerne do marketing social e o cenário atual de incerteza derivada da ocorrência, em escala global, do surto de COVID-19, o presente artigo apresenta o objetivo de descrever o contexto de inserção das práticas de marketing social na realidade brasileira atual, em que uma imensa mudança nas relações entre organizações e entre indivíduos se fez presente.

A análise apresentada se justifica, tendo em vista que são poucos os trabalhos relacionados à temática do marketing social em um contexto de pandemias, assim como à sua utilização em uma conjuntura de crises globais de saúde. A principal contribuição teórica, assim, se mostra no sentido de aprimorar a literatura sobre o tema, expondo os aspectos de uma intervenção comportamental em termos de aproveitar os preceitos do marketing social para prover maior bem-estar social em uma situação de amplo alcance.

\section{Metodologia}

Em termos metodológicos, o presente artigo foi organizado seguindo uma estrutura lógica e reflexiva, ressaltando a interpretação e a argumentação (Severino, 2000). Após iniciar expondo os conceitos basilares do marketing social e sua relação com a mudança de comportamento e a busca pela geração de bem-estar social, a metodologia aborda a análise de textos recentes sobre as situações mundial e brasileira no contexto do surto de COVID-19 e da quarentena que se seguiu em decorrência do 
consequente cenário de crise e transtorno. Os textos em questão incluem a literatura seminal e clássica a respeito do marketing social (eg. Kotler \& Lee, 2008; Kotler \& Zaltman, 1971; Andreasen, 1994), entre outros, cuja seleção contemplou obras selecionadas a partir de uma abordagem na qual se buscavam atributos de um tema cuja ocorrência é eventual - a pandemia de COVID-19 - e que fossem relacionados com outro, concentrado em aspectos sociais - o marketing social - , tendo por foco, assim, atributos organizacionais e comunitários. As referências foram interpretadas a fim de viabilizar o alcance de significado no contexto investigado, obtendo compreensão e desenvolvendo conhecimento que ajudasse a contextualizar os achados (Bowen, 2009). Assim, trechos significativos da literatura avaliada foram identificados, separando as informações pertinentes e não pertinentes. Neste caso, foi considerado pertinente o conteúdo que se relacionasse ao marketing social, a pandemias em geral e à de COVID-19 em particular, a mudanças de comportamento e a recomendações e políticas adotadas na conjuntura da pandemia. Após um exame inicial, lendo de forma minuciosa o material selecionado e interpretando-o à luz da realidade atual, foram discutidas as descobertas e os elementos investigados. Itens identificados como correspondentes - direta ou indiretamente - à atuação do marketing social são esmiuçados em pesquisa bibliográfica de natureza reflexiva, feita em obras atuais, que permitiu uma reflexão por intermédio de abordagem em que características presentes no contexto exposto - o surto de COVID-19 em tempos atuais - fossem analisadas e eventualmente vinculadas a aspectos do marketing social.

Esse roteiro segue os preceitos de Vergara e Carvalho Jr. (1995), que indicam que tal procedimento contribui para a sustentação de uma argumentação válida, assim como para a representação de eventuais apreensões e predisposições de análise no âmbito da produção científica. Corroborando Boccato (2006, p. 266), tal método de pesquisa busca contribuir na ponderação relacionada a um problema por meio de conteúdo teórico já publicado, "analisando e discutindo as várias contribuições científicas". 0 autor ressalta ainda que mediante tal pesquisa é possível obter "subsídios para o conhecimento sobre o que foi pesquisado, como e sob que enfoque e/ou perspectivas foi tratado o assunto apresentado na literatura científica" (Boccato, 2006, p. 266).

\section{Marketing Social e Bem-Estar da Sociedade}

Ainda que haja uma percepção de que o marketing social se refere a uma atuação promocional fundamentada prioritariamente em elementos de comunicação (McDermott, Stead, \& Hastings, 2005), cabe compreender sua concepção inicial e principais características.

0 termo "marketing social" surgiu na literatura de marketing quando Kotler e Zaltman (1971, p.5) definiram essa vertente como referente à concepção e implementação de ações e planejamentos realizados a fim de influenciar a receptividade de ideias sociais. Isto seria um indicativo de que o planejamento de produtos/serviços, bem como o de seus preços, divulgação e distribuição deveriam considerar a utilização de técnicas próprias do marketing no sentido de transformar empreendimentos de cunho social em estratégias capazes de gerar uma resposta oportuna do público-alvo.

Derivada dessa definição adveio a interpretação de que o marketing social seria referente a uma adaptação de técnicas do marketing tradicional para influenciar certos públicos-alvo para que agissem espontaneamente com a meta de "melhorar o seu bem-estar pessoal e o da sociedade da qual fazem parte" (Andreasen, 1994, p.110).

Mesmo que o marketing social se apresente como um conceito em expansão, devido a "um campo lotado de definições existentes" (Dann, 2010, p.147), cabe ressaltar sua relação com a busca por um desenvolvimento expressivo da sociedade, em especial no que se refere a aspectos educacionais, salubres e de geração de circunstâncias proveitosas aos membros de uma sociedade (Porter \& Kramer, 2006). Também os direitos humanos mostram afinidade com a abordagem do marketing social, em especial na conjuntura de uma pandemia como a de COVID-19. Os direitos humanos apresentam uma base moral e legal que favorece planejamentos abrangentes, o que ajuda no sentido de definir ideologias sociais concorrentes, mas com pontos em comum. Isto pode ocorrer com foco em proteção, respeito e realização, o que agrega um direcionamento para as considerações complexas da busca pelo bem-estar social, como preconizado na teoria do marketing social (Szablewska \& Kubacki, 2019).

A abordagem apresentada por Szablewska e Kubacki (2019) expõe que certos princípios identificados pelos autores como sendo de (1) transparência e responsabilidade, (2) igualdade e nãodiscriminação e (3) participação e inclusão - identificam as principais considerações de direitos humanos a serem levadas em consideração ao desenvolver e aplicar estratégias de marketing social para garantir que este atenda ao seu critério definidor, o que implica que "os objetivos do profissional de marketing social se relacionam com o bem-estar da comunidade" (Donovan \& Henley, 2010, p. 1), e não com os lucros de alguma organização.

A principal característica do marketing social é a adaptação ou adoção de condutas ou atividades que permitam a indução de mudanças no comportamento de um público-alvo, para que se alcance uma 
determinada meta social (Dann, 2010). Assim, entende-se que, havendo uma abordagem com foco na mudança de comportamento dos indivíduos, o marketing social passa a ser compreendido como um processo de âmbito social relacionado a uma intervenção e capaz de conduzir um mercado-alvo à realização de uma ação que acarrete bem-estar social no longo prazo.

Tal busca por bem-estar considera a progressiva demanda dos membros da sociedade no sentido de que corporações e empreendedores atuem conforme práticas socialmente responsáveis. Com tal propósito, é necessário um incentivo à aceitação de ideias ou comportamentos sociais que incitem ações benéficas para a sociedade e modifiquem comportamentos perniciosos (Vázquez, 2006), especialmente em uma situação de adversidade ou crise.

\section{Relação entre Preceitos do Marketing Social e a Crise do Covid-19}

Diversos gestores de marketing compreendem que ferramentas de marketing social são adequadas em situações nas quais organizações utilizam, paralelamente, estratégias próprias do marketing e ações de caráter social no intuito não de obter resultado financeiro, mas de gerar benfeitorias à sociedade (Zenone, 2006). Neste estudo, o foco recairá principalmente nos aspectos sociais (ligados à saúde, em particular, e outros de tal natureza, relacionados à comunidade), psicográficos (relacionados ao estilo de vida e à personalidade dos indivíduos), político-legais (relacionados a normas a serem cumpridas) e demográficos do marketing social, principalmente, por se tratar de uma situação de adversidade desencadeada por uma pandemia, isto é, um evento raro.

Em uma situação de crise, é comum que se realizem planejamentos característicos e que se definam estratégias específicas para minorar danos ou aproveitar oportunidades. Em tal conjuntura, o risco passa a importar e as ações a serem tomadas muitas vezes objetivam alcançar uma menor avaria em vez de um resultado promissor. Ademais, instabilidades sociais podem fornecer condições para um crescimento posterior, observados certos quesitos que permitam tirar proveito de situações específicas - como na pandemia de COVID-19, iniciada no final de 2019 e que acometeu praticamente todos os cidadãos do mundo, de forma direta ou indireta, sendo fortemente percebida também no Brasil.

0 surto iniciado em dezembro de 2019 indicou o potencial de uma variante do coronavirus. De forma resumida, pode-se citar a cidade de Wuhan, capital da província de Hubei, na China, como o local de início do que viria a se tornar uma pandemia de grande magnitude (Stratton, 2020).

A versão amplamente aceita indica que os primeiros casos de COVID-19 em humanos advieram de transmissão animal, tendo em seguida ocorrido a transmissão entre seres humanos, alcançando dimensões intercontinentais devido a viagens de indivíduos (Stratton, 2020). No Brasil, o primeiro caso confirmado ocorreu em 26 de fevereiro de 2020 e gerou apreensão, dado o potencial de transmissão por casos assintomáticos, o que afeta a aptidão de prevenir a propagação do vírus (Croda \& Garcia, 2020), em especial em um país de dimensões continentais como o Brasil.

Como surtos de doenças infecciosas são difíceis de ser reconhecidos por agências governamentais por apresentarem um início gradual sem danos relacionados à infraestrutura, como grandes construções, estradas e viadutos, é necessário que os governos apoiem as agências de saúde em seus respectivos países e regiões a fim de alterar e ajustar o comportamento humano, em vez de ter como foco o financiamento e o reparo da citada infraestrutura como forma de proporcionar alívio econômico e comercial, uma vez que, dada a ausência de tratamento médico totalmente seguro e eficaz no caso em tela, a pandemia de COVID-19 aparentemente só pode ser mitigada por meio de mudanças intensas e rápidas de comportamento (Betsch, 2020; Stratton, 2020).

Tais mudanças de comportamento refletem a distinção do marketing social da promoção ordinária de uma causa social, cujo foco costuma se dar em termos de colaborar com a obtenção de recursos ou recrutar voluntários para alguma ação (Kotler \& Lee, 2008). No domínio das ações de marketing social no atual contexto de crise causada pelo surto de COVID-19, deve-se observar a mudança de comportamento da população em termos de melhorar a estrutura emocional da sociedade, assim como, em prazo mais longo, se observa o foco nas consequências ligadas ao desenvolvimento individual e social humano (Wasan \& Tripathi, 2015). É ainda relevante advertir que há responsabilidades individuais e coletivas, cujas decisões podem envolver os membros de uma sociedade, assim como as consequências que advêm dos atos individuais ou coletivos, tanto positivas quanto negativas, podem afetar a toda uma comunidade (Misoczky, Camara, \& Böhm, 2017), o que indica a necessidade de que os comportamentos empreendidos busquem o melhor resultado para todos.

A natureza das ações do marketing social, como mencionado, tencionam colaborar no sentido de influenciar a conduta do público a quem tais ações são dirigidas. Muitas vezes esse público-alvo é chamado de adotantes-alvo, uma vez que o que se deseja não é a compra de um produto ou serviço, mas a adoção de certas práticas benéficas à sociedade (Kamlot \& Schmitt, 2015). Nesse particular, pode-se sublinhar a relação existente entre o marketing social e a responsabilidade social, pois "de um 
modo geral, a responsabilidade social demanda que os profissionais de marketing aceitem a obrigação de dar o mesmo peso ao lucro, à satisfação do consumidor e ao bem-estar social ao avaliar o desempenho de uma empresa" (Boone \& Kurtz, 2015, p.105).

Detalhando a conjuntura que advém da situação pandêmica global atualmente e que acomete a realidade brasileira, nota-se que a crise demonstra a particularidade de demandar uma mudança de comportamento em larga escala (Van Bavel et al., 2020), como apresentado a seguir.

\section{Mudança de Comportamento no Contexto da Pandemia do Covid-19}

Betsch (2020) menciona uma pesquisa recente, em que se observou que a disposição para fazer sacrifícios no cotidiano, objetivando "achatar a curva" e diminuir a carga para o sistema de saúde, era elevada. E, quando a motivação era proteger outras pessoas vulneráveis, a disposição de atuar com restrições no cotidiano se mostrava ainda maior, o que indica uma percepção importante: compartilhar a norma social constitui uma estratégia chave para a comunicação no âmbito da saúde pública. Tais informações podem ser um indicativo sobre a resposta ao surto, pois se observa que saber que a maioria das pessoas adotaria um comportamento de restringir ações às quais estavam acostumadas para proteger os outros facilita a defrontar a incômoda questão "eu sou o único a fazer isso?", podendo propagar a solidariedade necessária em um momento no qual todos podem sofrer os efeitos colaterais de uma crise, mesmo que não relacionados à saúde propriamente dita.

No caso particular da pandemia do COVID-19 e de suas consequências no contexto brasileiro, a fim de que seja possível minorar os problemas decorrentes da crise, observam-se os comportamentos relacionados aos aspectos econômico - incluindo desemprego, produtividade e (queda de) investimentos - e social - referente a bem-estar social, educação e transporte, entre outros.

No âmbito dos efeitos econômicos - diretos e indiretos -, podem ser observados alguns aspectos relevantes. Em termos de prevenção, há as práticas com capacidade de atenuar riscos percebidos, como o uso de máscaras, o que acentua a venda destes equipamentos. No que se refere às implicações econômicas em si, observam-se a descontinuidade de negócios; a interrupção em cadeias de suprimentos; o comportamento público visando à prevenção do contágio; proibições de comércio e de viagens, entre outras; e as consequências da pandemia e da quarentena, como supermercados, cinemas e companhias aéreas permanentemente fechados, perdas de emprego, atrasos na educação fundamental e no ensino superior etc. (Evans, 2020; OMS, 2020).

Analisando os efeitos de ordem social do COVID-19, observam-se o aumento nas desigualdades sociais, difícil acesso a medicamentos e alimentos, sedentarismo mais elevado, potencial sentimento de depressão, maior consumo de álcool, solidão derivada do distanciamento de entes queridos, entre outros (Continetti, 2020).

$\mathrm{Na}$ literatura atual a respeito das ações consideradas mais eficientes no combate ao COVID-19, observam-se as recomendações expostas no Quadro 1, em que ponderações são mostradas, com base em trabalhos recentes e políticas adotadas que podem colaborar na realidade nacional.

\section{Quadro 1 - Recomendações relacionadas ao combate ao COVID-19}

\begin{tabular}{|l|l|l|}
\hline \multicolumn{1}{|c|}{$\begin{array}{c}\text { Recomendações e políticas } \\
\text { adotadas }\end{array}$} & \multicolumn{1}{|c|}{ Fonte } & \multicolumn{1}{|c|}{$\begin{array}{c}\text { Apreciação e ponderações com base no } \\
\text { marketing social }\end{array}$} \\
\hline Distanciamento físico e social, \\
$\begin{array}{l}\text { cujas medidas reduzem a } \\
\text { demanda de consumo, limitando } \\
\text { gastos em lazer e } \\
\text { entretenimento }\end{array}$ & $\begin{array}{l}\text { OMS, 2020; } \\
\text { Euromonitor, } \\
2020 ; \text { Watkins, } \\
2020\end{array}$ & $\begin{array}{l}\text { As medidas de distanciamento social e físico } \\
\text { visam ao retardamento da propagação da } \\
\text { doença, interrompendo as cadeias de } \\
\text { transmissão do COVID-19. Recomenda-se a } \\
\text { distância física de ao menos um metro e a } \\
\text { redução do contato com eventuais superfícies } \\
\text { contaminadas, incentivando uma conexão } \\
\text { social virtual entre grupos sociais, o que } \\
\text { denota uma alteração no comportamento } \\
\text { usualmente seguido pelos indivíduos. }\end{array}$ \\
\hline
\end{tabular}




\begin{tabular}{|c|c|c|}
\hline $\begin{array}{l}\text { Introdução de acordos de } \\
\text { trabalho flexíveis }\end{array}$ & OMS, 2020 & $\begin{array}{l}\text { A utilização do teletrabalho e do ensino a } \\
\text { distância (suportada por leis e normas), assim } \\
\text { como a redução de aglomerações humanas e o } \\
\text { fechamento de certas instalações e serviços } \\
\text { não essenciais, facilita a blindagem e a } \\
\text { proteção, em especial para grupos } \\
\text { vulneráveis. }\end{array}$ \\
\hline $\begin{array}{l}\text { Fechamento de instalações e } \\
\text { serviços não essenciais }\end{array}$ & OMS, 2020 & $\begin{array}{l}\text { Organizar locais de trabalho de modo a } \\
\text { garantir a distância física entre as pessoas, } \\
\text { como turnos escalonados ao longo do tempo, } \\
\text { ou converter o serviço presencial em entrega } \\
\text { domiciliar pode ajudar a manter mais } \\
\text { empresas abertas. }\end{array}$ \\
\hline $\begin{array}{l}\text { Evitar aglomerações de pessoas } \\
\text { a fim de proporcionar uma } \\
\text { redução no contato direto entre } \\
\text { membros de uma mesma } \\
\text { comunidade }\end{array}$ & $\begin{array}{l}\text { Ebrahim et al., } \\
2020\end{array}$ & $\begin{array}{l}\text { Não é preciso que pessoas se aglomerem para } \\
\text { limitar danos sociais ou econômicos, podendo } \\
\text { apoiar a resiliência comunitária e a saúde } \\
\text { mental, bem como proteger o acesso a bens/ } \\
\text { serviços essenciais e limitar o impacto } \\
\text { econômico da permanência em casa, com uma } \\
\text { mudança de comportamento, no âmbito } \\
\text { psicográfico, do estilo de vida. } \\
\text { Nesse caso, observa-se que mudar a conduta } \\
\text { de realizar aglomerações em situações em que } \\
\text { eram habituais indica um câmbio } \\
\text { comportamental, como apregoado pelo } \\
\text { marketing social, visando a gerar bem-estar } \\
\text { social futuro. }\end{array}$ \\
\hline $\begin{array}{l}\text { Restrições em movimentações, } \\
\text { localmente ou em escala } \\
\text { nacional. Fechamento de áreas } \\
\text { públicas, como restaurantes, } \\
\text { shopping centers, academias, } \\
\text { cinemas etc. e adiamento de } \\
\text { eventos de grande porte, como } \\
\text { os Jogos Olímpicos de Tóquio. }\end{array}$ & $\begin{array}{l}\text { OMS, 2020; } \\
\text { Euromonitor } \\
(2020)\end{array}$ & $\begin{array}{l}\text { As medidas sociais - inclusive as de saúde } \\
\text { pública não farmacológicas, como redução na } \\
\text { locomoção e acesso a áreas e locais público, } \\
\text { incentivo à higiene das mãos e adoção de } \\
\text { máscaras faciais - devem elevar o asseio e a } \\
\text { salubridade em geral, e tornar a tarefa de } \\
\text { rastreamento de contatos mais simples, com } \\
\text { redução no número de contatos. Neste caso, o } \\
\text { que se observa em termos da teoria do } \\
\text { marketing social é relacionado a uma ação que } \\
\text { "tem como objetivo principal atenuar ou } \\
\text { eliminar problemas sociais e as carências da } \\
\text { sociedade relacionadas principalmente às } \\
\text { questões de higiene e saúde pública, de } \\
\text { trabalho, educação, habitação, transportes e } \\
\text { nutrição" (Vaz, 1995, p.280). }\end{array}$ \\
\hline
\end{tabular}




\begin{tabular}{|c|c|c|}
\hline $\begin{array}{l}\text { Medidas para permanência em } \\
\text { casa de grupos vulneráveis, } \\
\text { como idosos, diabéticos, } \\
\text { hipertensos etc. }\end{array}$ & OMS, 2020 & $\begin{array}{l}\text { As medidas devem visar à manutenção de } \\
\text { conexões pessoais/profissionais por meios } \\
\text { virtuais, incluindo computadores e celulares. } \\
\text { Quando necessário, cabe ao(s) governo(s) } \\
\text { auxiliar financeiramente os que dependam de } \\
\text { renda e não possam trabalhar, por exemplo } \\
\text { definindo novas política públicas adequadas. } \\
\text { Aqui se observa a defesa de uma causa - a } \\
\text { defesa da saúde dos mais vulneráveis -, como } \\
\text { abordado por Kotler e Roberto (1992) em sua } \\
\text { definição do marketing social, sendo este } \\
\text { "uma tecnologia de gestão da mudança social, } \\
\text { associada ao projeto, implantação e controle } \\
\text { de programas voltados para o aumento da } \\
\text { disposição de aceitação de uma ideia ou } \\
\text { prática social em um ou mais grupos de } \\
\text { adotantes escolhidos como alvo" (Kotler \& } \\
\text { Roberto, 1992, p.25) }\end{array}$ \\
\hline $\begin{array}{l}\text { Reorganização coordenada de } \\
\text { redes de saúde e serviços sociais } \\
\text { para proteger hospitais. } \\
\text { Mudanças nos serviços } \\
\text { funerários para minimizar a } \\
\text { quantidade de pessoas } \\
\text { presentes e a consequente } \\
\text { exposição aos fluidos corporais } \\
\text { dos doentes. }\end{array}$ & $\begin{array}{l}\text { OMS, 2020; } \\
\text { Ebrahim et al., } \\
2020\end{array}$ & $\begin{array}{l}\text { A reorganização coordenada dos serviços de } \\
\text { saúde e sociais é essencial para avaliar/testar } \\
\text { as pessoas rapidamente, tratar os pacientes } \\
\text { eficazmente e proteger instalações } \\
\text { hospitalares e profissionais de saúde. Como } \\
\text { indicado por Lefebvre (p.14), "é comum o uso } \\
\text { do marketing social em programas de saúde } \\
\text { pública" pelo fato de estratégias de marketing } \\
\text { social terem se tornado "parte das estratégias } \\
\text { nacionais destinadas a melhorar a saúde } \\
\text { pública e o bem-estar social". }\end{array}$ \\
\hline $\begin{array}{l}\text { Medidas de proteção individual } \\
\text { contra o COVID-19, como } \\
\text { lavagem frequente das mãos, } \\
\text { evitar espalhamento da tosse, } \\
\text { abraços etc. }\end{array}$ & Betsch, 2020 & $\begin{array}{l}\text { A maioria das medidas contra o coronavírus } \\
\text { são utilizadas em conjunto com medidas de } \\
\text { proteção individual, como as citadas. }\end{array}$ \\
\hline $\begin{array}{l}\text { Testagem de todos os casos } \\
\text { suspeitos de COVID-19 sempre } \\
\text { que possível, isolando } \\
\text { prontamente os casos. Rastrear } \\
\text { contatos na medida mais ampla } \\
\text { possível e garantir a quarentena } \\
\text { deles durante o período de } \\
\text { incubação. }\end{array}$ & OMS, 2020 & $\begin{array}{l}\text { À medida que medidas sociais são levantadas, } \\
\text { é primordial continuar a identificar } \\
\text { ocorrências, realizando isolamento para casos } \\
\text { de COVID-19 e quarentena de contatos, para } \\
\text { responder a casos que ressurjam ou sejam } \\
\text { importados. }\end{array}$ \\
\hline
\end{tabular}

Fontes: Adaptado de Kotler \& Roberto, 1992; Vaz,1995; Lefebvre, 2013; Betsch, 2020; Ebrahim et al., 2020; Euromonitor, 2020; OMS, 2020

Observa-se que, a partir do conteúdo do Quadro 1, a mudança de comportamento relacionada a ações do cotidiano dos brasileiros deve enfrentar e superar um obstáculo considerável: os hábitos (Lunn et al., 2020). Estes se mostram operantes fora das ações conscientes das pessoas, e difíceis de alterar apenas com conhecimento e educação. Um exemplo é citado por Edwards et al. (2012), que mencionam que, mesmo em ambientes inóspitos de saúde, tentativas de melhorar a higiene das mãos assim como outros comportamentos de controle de infecções - por meio da educação e da conscientização têm impactos limitados e de curto prazo. Assim, mostra-se relevante a atuação das autoridades e dos gestores a fim de alterar os comportamentos que possam causar problemas no bemestar futuro da sociedade - agindo, assim, de acordo com o que é determinado no domínio do marketing social.

Algumas soluções podem ser propostas visando à alteração do comportamento de cidadãos e organizações nacionais, uma vez que, atingido um estado de bem-estar condizente com as 
necessidades populacionais, estarão disponíveis condições para que todos possam ter acesso a oportunidades mais promissoras que as atuais. Para Kotler e Lee (2008), essas soluções podem se referir à alteração de comportamentos (como manter distância segura dos demais indivíduos), inovações tecnológicas e descobertas científicas (como as vacinas e seu aprimoramento), pressões econômicas (como fornecer pagamentos à população, exigindo em contrapartida o isolamento social), a criação de novas normas e leis (como a definição de horários restritos no funcionamento do comércio) e a própria educação dos cidadãos (no sentido de compreenderem a gravidade de uma aglomeração em plena pandemia, por exemplo).

Do ponto de vista da criação ou alteração de políticas públicas, cabe aos governantes perceber que reconstruir uma estrada ou financiar um abrigo para indivíduos em situação habitacional precária, por exemplo, é muito mais fácil do que convencer uma população - ou parte desta - a mudar seu comportamento habitual, permitindo assim uma limitação da propagação da doença (Stratton, 2020). O hábito, como citado, constitui uma barreira complicada de ser transposta, em particular pelos brasileiros, que muitas vezes permanecem atuando como se não houvesse um real perigo decorrente da pandemia e desconsiderando os benefícios futuros a partir da mudança de comportamento, o que aparentemente expõe o chamado paradoxo da prevenção, o qual, nas palavras de Couto et al. (2021, p.6),

representa o conflito entre interesses coletivos - que requerem ampla mudança da sociedade - e interesses individuais - que frequentemente consideram que as mudanças exigidas não trazem benefícios significativos. Segundo sua formulação, as ações preventivas (como as preconizadas pela OMS) e adotadas de formas diferenciadas pelos governos (Hamilton \& Safford, 2020) podem ser consideradas como amplamente seguras, tendo como base para a aceitação seu razoável e pressuposto benefício. A garantia dos seus resultados benéficos, porém, não equivale a uma incondicional postura afirmativa de engajamento por parte de indivíduos e grupos sociais.

Convém aqui frisar a observação de Martins et al. (2021, p.4) sobre o "descaso [dos brasileiros] com seus conterrâneos". Os autores citam que "em meio à pandemia do novo coronavírus no Brasil, o comportamento do brasileiro agravou a disseminação do vírus pelo país". Portanto, pode ser necessário que um "novo" comportamento deva ser definido e difundido por prefeitos e governadores, mesmo com penalidades àqueles que o descumprirem. Isso porque a solidariedade na sociedade ainda demonstra carência por um nível de conscientização mais elevado quanto a seus benefícios, nos âmbitos moral, ético e jurídico, tanto pelos indivíduos em si, quanto por órgãos governamentais (Carvalho \& Miranda, 2021). Algumas recomendações, apresentadas a seguir, se fazem necessárias nesse sentido:

- Considerando as viagens como um importante fator singular que coopera para a propagação de doenças, o cancelamento e/ou proibição delas em larga escala pode contribuir para uma redução considerável da difusão do vírus em questão (Ebrahim et al., 2020). Ainda que uma proibição total de viagens possa também afetar aquelas de funcionários essenciais e a movimentação oportuna de suprimentos, é indicado considerar a possibilidade de uma mudança no comportamento de viajantes eventuais o quanto antes, além de uma frequência menor de transportes públicos coletivos, ou mesmo uma restrição das rotas.

- Para que menos contatos pessoais ocorram, o cancelamento de grandes eventos que congreguem multidões, como shows, é urgente - e deve-se contar com uma alteração nos hábitos daqueles que se acostumaram a participar de tais eventos ao vivo, passando a entender que a participação remota, por computadores ou smartphones, pode ser igualmente viável.

- A conversão de serviços presenciais para aqueles que permitam entrega em domicílio - caso de restaurantes, supermercados etc. - pode ajudar a manter mais empresas funcionando (OMS, 2020).

- Não há como dissociar as escolhas relacionadas à luta contra o vírus em termos sociais de suas consequências econômicas; contudo, em caso de conflito entre objetivos sociais e comerciais, os primeiros devem ter precedência, com foco no bem social, o qual implica na aplicação de uma abordagem baseada nos direitos humanos, observando o papel do marketing social de influenciar mudanças voluntárias de comportamento, oferecendo escolhas conducentes a tais mudanças (Szablewska \& Kubacki, 2019). A ajuda financeira de entes governamentais aos despossuídos deve ser considerada, dada a vultosa parcela de trabalhadores informais cuja fonte de renda é abalada devido ao distanciamento social. 
- É indicado, em diversos setores, que se definam novos horários de trabalho e rotatividade de colaboradores, buscando diminuir a densidade social, o que contribui para minimizar a propagação da doença (Ebrahim et al., 2020).

\section{Considerações Finais}

A partir das considerações sobre a situação derivada do surto de COVID-19, algumas considerações podem ser mencionadas perante os dados e fatos apresentados sobre a realidade brasileira presente. Ponderando a atuação em termos de marketing social, focada em uma alteração no comportamento potencialmente lesivo à sociedade, e com vistas a melhorar o bem-estar desta, algumas indicações podem ser apresentadas.

Inicialmente, recomenda-se aos países que enfrentam um potencial espalhamento do COVID-19, e às localidades brasileiras em particular, que considerem atuar no sentido de exigir o fechamento de locais de trabalho não essenciais, além das medidas de distanciamento interpessoal, para reduzir ao máximo a taxa de transmissão. Os gestores da saúde devem também projetar as atividades do período de encerramento do controle do surto, considerando eventuais características epidêmicas da doença, o período de incubação e as rotas de transmissão dentro do país e originárias do exterior.

Muito importante também é a prevenção de pessoas com infecções assintomáticas que podem vir a espalhar a doença, em especial em ambientes como clusters familiares e similares, demandando assim a adoção de medidas mitigatórias e de proteção, buscando o isolamento preemptivo dos suspeitos, assim como o reforço do distanciamento social e da consolidação de seus hábitos de higiene (Silva et al., 2020). No caso, os governantes devem aproveitar o período de encerramento das contenções para obter informações das pessoas e propagar campanhas de educação e triagem comunitária, mantendo um contato ativo, o qual pode permitir rastreamentos e potenciais atividades de isolamento que facilitem o alcance de resultados mais profícuos (Chen, 2020).

Além de argumentos éticos em favor da adoção de tal abordagem, há também uma racionalização pragmática viável, incluindo um aumento na eficácia e legitimidade das estratégias e intervenções de marketing social. Empregar uma abordagem baseada em direitos humanos ajuda no gerenciamento de riscos e oportunidades, além de oferecer um método particularmente útil para lidar com questões desafiadoras. Uma abordagem baseada em direitos humanos oferece aos profissionais de marketing social um guia prático que tem como implicações a facilitação do reconhecimento das expectativas da sociedade brasileira e a ajuda no desenvolvimento de maneiras mais sustentáveis de abordar problemas sociais e alterar comportamentos, considerando as referências universais proclamadas pelos princípios fundamentais dos direitos humanos: transparência e responsabilização; igualdade e não-discriminação; e participação e inclusão.

\section{Referências}

Abratt, R., \& Sacks, D. (1988). The Marketing Challenge: Towards Being Profitable and Socially Responsible. Journal of Business Ethics , 7(7), 497-507.

Andreasen, A. R. (1994). Social Marketing: Its Definition and Domain. Journal of Public Policy \& Marketing, 13(1), 108-114.

Betsch, C. (2020). How behavioural science data helps mitigate the COVID-19 crisis. Nature Human Behaviour, 2020. Recuperado de https://doi.org/10.1038/s41562-020-0866-1

Boccato, V. R. C. (2006). Metodologia da pesquisa bibliográfica na área odontológica e o artigo científico como forma de comunicação. Rev. Odontol. Univ. Cidade São Paulo, 18(3), 265-274.

Boone, L. E. \& Kurtz, D. L. Contemporary Marketing, 17 ed. Mason: Cengage Learning, 2015.

Bowen, G. (2009). Document analysis as a qualitative research method. Qualitative Research Journal, 9 (2), 27-40.

Carvalho, M. H. P. \& Miranda, M. L. L. (2021). O princípio da solidariedade no enfrentamento da COVID-19 no Brasil. Cadernos Ibero-americanos de Direito Sanitário, 10(1), 13-38.

Chen, S. et al. (2020). COVID-19 control in China during mass population movements at New Year. The Lancet, 395, 764-766. Recuperado de https://www.thelancet.com/action/showPdf? pii=S0140-6736\%2820\%2930421-9.

Continetti, M. The Social Costs of COVID-19. (2020). National Review, LXXII(7). Recuperado de https:// www.nationalreview.com/magazine/2020/04/20/the-social-costs-of-covid-19\%E2\%80\%88/.

Couto, M. T., Barbieri, C. L. A., \& Matos, C. C. S. A. (2021). Considerações sobre o impacto da covid-19 na relação indivíduo-sociedade: da hesitação vacinal ao clamor por uma vacina. Saúde e Sociedade, 30(1), e200450, 1-11.

Croda, J. H. R. \& Garcia, L. P. (2020). Resposta imediata da Vigilância em Saúde à epidemia da COVID-19. Epidemiologia e Serviços de Saúde, 29(1). Recuperado de https://www.scielosp.org/article/ress/ 2020.v29n1/e2020002/pt/ 
Dann, S. (2010). Redefining social marketing with contemporary commercial marketing definitions. Journal of Business Research, 63(2), 147-153.

Donovan, R. \& Henley, N. (2010). Principles and practice of social marketing: An international perspective. Cambridge: Cambridge University Press.

Ebrahim, S.H. et al. (2020). Covid-19 and community mitigation strategies in a pandemic. BMJ, 368(m1066).

Edwards, R., et al. (2012). Optimisation of infection prevention and control in acute health care by use of behaviour change: A systematic review. The Lancet Infectious Diseases, 12(4), 318-329.

Euromonitor. (2020). The impact of coronavirus on the global economy. Euromonitor International, 1-34.

Evans, 0. (2020). Socio-economic impacts of novel coronavirus: The policy solutions. BizEcons Quarterly, 7, 3-12.

Kamlot, D. (2012). Interferência do Estado na sociedade: uma visão de marketing social. Revista da ESPM, 19(3), 78-83.

Kamlot, D. (2017). Resiliência organizacional e marketing social: uma avaliação de fundamentos e afinidades. Cadernos EBAPE.BR, 15 (ed.esp.), 482- 495.

Kamlot, D. \& Schmitt, V.G.H. (2015). O comércio justo nas práticas de marketing social das grandes empresas. Revista de Gestão Social e Ambiental - RGSA, 9(3), 63-79.

Kotler, P. \& Lee, N. (2008). Social marketing: influencing behaviors for good. Thousand Oaks: Sage.

Kotler, P. \& Roberto, E. L. (1992). Marketing Social: estratégias para alterar o comportamento público. Rio de Janeiro: Campus.

Kotler, P. \& Zaltman, G. (1971). Social marketing: an approach to planned social change. Journal of Marketing, 35(3), 3-12.

Lefebvre, R. C. (2013). Social Marketing and Social Change. San Francisco: Jossey-Bass.

Lunn, P. D. et al. (2020). Using behavioural science to help fight the coronavirus: A rapid, narrative review. Journal of Behavioral Public Administration, 3(1), doi: 10.30636/jbpa.31.147.

Martins, L. S. et al. (2020). Pandemia no Brasil: a interrelação entre comportamento anti(ético), decisões políticas e características histórico-sociais. Anais do Congresso Nacional Universidade EAD e Software Livre, 2(11). 1-6.

McDermott, L., Stead, M., \& Hastings, G. (2005). What Is and What Is Not Social Marketing: The Challenge of Reviewing the Evidence. Journal of marketing Management, 21(5-6), 545-553.

Misoczky, M.C., Camara G.D., \& Böhm, S. (2017). Organizational practices of social movements and popular struggles: Understanding the power of organizing from below. Qualitative Research in Organizations and Management: An International Journal, 12(4), 250-261.

OMS - ORGANIZAÇÃO MUNDIAL DA SAÚDE. (April, 2020). Coronavirus disease 2019 (COVID-19) Situation Report, 72. Recuperado de https://www.who.int/docs/default-source/coronaviruse/ situation-reports/20200401-sitrep-72-covid-19.pdf?sfvrsn=3dd8971b 2.

Porter, M. E. \& Kramer, M. R. (2006). Strategy and Society: The Link Between Competitive Advantage and Corporate Social Responsibility. Harvard Business Review, 84(12), 78-92.

Severino, A. J. (2000). Metodologia do trabalho científico. 21.ed. São Paulo: Cortez.

Silva, J. H. et al. (2020). Descrição de um cluster da COVID-19: o isolamento e a testagem em assintomáticos como estratégias de prevenção da disseminação local em Mato Grosso, 2020. Epidemiol. Serv. Saude, 29(4):e2020264, 1-9.

Stratton, S. J. (2020). COVID-19: Not a Simple Public Health Emergency. Prehospital and Disaster Medicine, 35(2), 119.

Szablewska, N. \& Kubacki, K. (2019). A Human Rights-Based Approach to the Social Good in Social Marketing. Journal of Business Ethics, (155), 871-888.

Van Bavel, J. J. et al. (2020, in press). Using social and behavioural science to support COVID-19 pandemic response. Nature Human Behavior.

Vaz, G. N. (1995). Marketing Institucional: O Mercado de Ideias e Imagens. São Paulo: Pioneira.

Vergara, S. C. \& Carvalho JR., D. S. (1995). Nacionalidade dos autores referenciados na literatura brasileira sobre organizações. In: Encontro da Anpad, 19, 1995, João Pessoa. Anais... Rio de Janeiro: Anpad, 6. Organizações, 169-188.

Vázquez, M. A. (2006). Marketing social corporativo. Edición electrónica. Ed. por Eumed.net. Recuperado de www.eumed.net/libros/2006/mav/.

Wasan, P.G. \& Tripathi, G. (2015). Revisiting social marketing mix: a socio-cultural perspective. Journal of Services Research, 14(2), 127-144.

Watkins, J. (2020). Preventing a covid-19 pandemic: We need to think beyond containment. BMJ, 368, m810.

Zenone, L.C. (2006). Marketing Social. São Paulo: Thomson. 